\title{
Three to Five Years
}

National Cancer Institute

\section{Source}

National Cancer Institute. Three to Five Years. NCI Thesaurus. Code C148657.

An indication that something has lasted, or occurred during, three to five years. 